М. Л. Андреев abc

ORCID: 0000-0002-5170-7634

mikhailandreev1@gmail.com

${ }^{\text {a } И н с т и т у т ~ м и р о в о и ̆ ~ л и т е р а т у р ь ~}$

илм. А. М. Горького РАН (Россия, Москва)

${ }^{\mathrm{b}}$ Российская академия народного хозяйства

и государственной службь

при Президенте РФ (Россия, Москва)

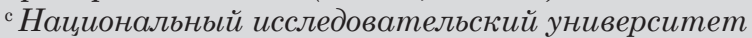

"Высшая школа эконолики" (Россия, Москва)

\title{
ДВА РУССКИХ «ДЕКАМЕРОНА»
}

Аннотация. В статье сопоставляются два перевода "Декамерона» Джованни Боккаччо - А. Н. Веселовского (1891-1892) и Н. М. Любимова (1970). Уникальность ситуации заключается в том, что новый перевод с течением времени не вытеснил старый и не был им оттеснен: оба перевода нашли место в современном книгоиздательском пространстве и, следовательно, как можно предположить, ориентированы на разные категории читателей. Веселовский в своем переводе придерживается принципа формальной верности подлиннику («буквализм»), что проявляется и на уровне отдельных внутрифразовых единиц (перевод «слово в слово»), и в сохранении синтаксического порядка. При этом искусственно состарить язык Веселовский не пытался. Любимов в целом придерживается принципов советской школы «творческого» перевода. Язык любимовского "Декамерона» это обобщенный литературный язык XIX-XX вв., умеренно инкрустированный славянизмами, без модернизаций и почти без словесной изобретательности, свойственной, к примеру, переводу Рабле. Какую-то особую дикцию для своего “Декамерона» он выработать не пытался, в отличие от Веселовского. Оба переводчика отказываются от воспроизведения богатого риторического инструментария Боккаччо. Веселовский порой подвергает язык существенным перегрузкам (хотя и не прямой ломке), но именно благодаря этому остранению, этому языковому сдвигу, этой дикции, не имеющей в русской языковой традиции прямых аналогов, заполняет ту пустоту, которая образована отсутствием в русской литературной традиции аналогов "Декамерона». Заполняет далеко не до конца, но в целом можно утверждать, что это принципиально иной, чем у Любимова, тип перевода, приближающий не оригинал к читателю, а читателя к оригиналу.

Ключевые слова: Дж. Боккаччо, «Декамерон», перевод, буквалистский перевод, творческий перевод, А. Н. Веселовский, Н. М. Любимов 
Для иитирования: Андреев М. Л. Два русских «Декамерона» // Шаги/Steps. Т. 5.

№ 3. 2019. С. 38-50. DOI: 10.22394/2412-9410-2019-5-3-38-50.

Статья поступила в редакиию 25 декабря 2018 г.

Принято к печати 6 марта 2019 г.

Shagi/Steps. Vol. 5. No. 3. 2019

M. L. Andreev abc

ORCID: 0000-0002-5170-7634

mikhailandreev1@gmail.com

${ }^{a}$ A. M. Gorky Institute of World Literature

of the Russian Academy of Sciences (Russia, Moscow)

${ }^{\mathrm{b}}$ The Russian Presidential Academy

of National Economy and Public Administration (Russia, Moscow)

${ }^{\mathrm{c}}$ National Research University

Higher School of Economics (Russia, Moscow)

\section{Two Russian DeCaMerons}

Abstract. The article juxtaposes two translations of Boccaccio's The Decameron - the one by Alexander N. Veselovsky (1891-1892) and the other by Nikolai M. Liubimov (1970). What is unique and noteworthy here is that, over time, the more recent translation neither displaced the older nor lost ground to it; both versions found their proper niches in today's book publishing market and hence, as one might infer, are intended for different categories of reader. Veselovsky, in his translation, keeps to the principle of formal fidelity to the original ('literalism'): this reveals itself both on the level of certain intra-phraseological units ('word-for-word' translation) and in preservation of the original syntactic order of the source text. Incidentally, Veselovsky did not attempt to artificially anachronize the language. Liubimov, on the other hand, follows, in the main, the principles of the Soviet school of 'creative' translation. The language of Liubimov's Decameron is the standard literary tongue of the $19^{\text {th }}-20^{\text {th }}$ centuries, which is moderately encrusted with Slavisms; it exhibits no modernizations, nor any particular verbal ingenuities that characterize, for instance, his translation of Rabelais. Unlike Veselovsky, Liubimov did not attempt to create a specific diction for his Decameron. Both translators refrain from re-creating the vast rhetorical array of Boccaccio. Veselovsky, at times, tugs at the language (though not outright violently); thanks to that technique of 'ostranenie' (defamiliarization), these linguistic displacements, this diction which has no direct analogs in the Russian tradition, he fills the void created by the lack of any counterparts of Decameron in the Russian literary tradition. 
Yet his action is far from complete; by and large, it is possible to argue that Veselovsky's translation principally differs from Liubimov's in that rather than bringing the source text to the target audience, it brings the audience to the source text.

Keywords: G. Boccaccio, Decameron, translation, literal translation, artistic translation, A. N. Veselovsky, N. M. Liubimov

To cite this article: Andreev, M. L. (2019). Two Russian Decamerons. Shagi/Steps, 5(3), 38-50. (In Russian). DOI: 10.22394/2412-9410-2019-5-3-38-50.

Received December 25, 2018

Accepted March 6, 2019

$\prod$ еревод «Декамерона» Джованни Боккаччо, принадлежащий А. Н. Beселовскому и вышедший при его жизни двумя изданиями (1891-1892 и 1896), - явление в русской переводческой традиции уникальное. Уникальность его в том, что это единственный прозаический перевод классического литературного памятника, который сделан в XIX в. и регулярно перепечатывается вплоть до наших дней. В этом отношении он сопоставим с поэтическими памятниками, с «Илиадой» Гнедича и «Одиссеей» Жуковского, и, подобно им, успешно выдержал конкуренцию с позднейшими переводами.

Со временем и сам перевод Веселовского стал считаться классическим («он вошел в классику русской культуры и зажил с ней одной жизнью» [Хлодовский 1992: 337]). Наряду с образцовой точностью особо отмечались и его выдающиеся литературные достоинства. Это, правда, не касается первых откликов на публикацию перевода. Все их авторы почти единодушно были несколько обескуражены тем, что сам переводчик обозначал как «шероховатости стиля», «накопления эпитетов», «длинно вьющуюся фразу» [Веселовский 1992: хіi]. (Например: «...обаяния неподражаемой итальянской речи в русском издании не чувствуется. Верность, точность, правильность перевода не заменяют своеобразных красот флорентинского слога - даже при условии такой виртуозной и изысканно-добросовестной передачи оригинального текста, какою, без самомнения [sic!], должно считать перевод проф. А. Н. Веселовского» [Новые книги 1892: 52]). Затем, правда, эти голоса умолкли. На литературную безупречность перевода указывал и В. Ф. Шишмарев в 1920-е годы («Веселовский был не только замечательным исследователем литературных памятников, но, когда хотел, и тонким стилистом, владевшим превосходно русским языком и располагавшим богатейшим словарем» [Шишмарев 1927: xxvi]), и М. П. Алексеев в 1930-е («...перевод “Декамерона” представляет собой замечательное явление русской художественной литературы, и не только переводной 〈..., перевод этот сделан с присущим Веселовскому замечательным чутьем русского языка и его стилистических возможностей» [Алексеев 1939: 548]), и А. Л. Штейн в 1950-е («Перевод А. Н. Веселовского справедливо считается значительным памятником русского переводческого искусства. Отмеченный глубоким проникновением в содержание и стиль книги, этот 
перевод доносит до читателя стилистическую манеру Боккаччо, лексическое богатство подлинника» [Штейн 1955: 24]), и Р. И. Хлодовский в 1990-е [Хлодовский 1992].

Иных мнений слышно почти не было. Только Штейн сопроводил свою хвалебную оценку оговоркой о том, что переводчик «несколько излишне» архаизировал язык перевода (что совершенно несправедливо: никакой архаизаторской установки у Веселовского не прослеживается), и еще Н. Б. Томашевский в преамбуле к первому изданию перевода Н. М. Любимова посетовал на «дословность и калькированный синтаксис» перевода Веселовского [Томашевский 1970: 663], что, впрочем, понятно, поскольку необходимость нового перевода надо было как-то обосновывать.

Новый перевод на какое-то время полностью вытеснил прежний из издательской практики: с момента выхода в свет перевода Любимова (1970) до 1988 г. перевод Веселовского не перепечатывался ни разу. Затем положение кардинальным образом изменилось: перевод Любимова оказался не вытеснен, но существенно потеснен (что, возможно, объясняется, хотя бы отчасти, и ситуацией с авторскими правами: наследникам Веселовского платить не надо). С 1988 по 2012 г. «Декамерон» Любимова переиздавался 24 раза, «Декамерон» Веселовского - 46, почти вдвое чаще.

Н. М. Любимов - пожалуй, самый знаменитый русский переводчик западноевропейской прозы, в основном французской, но не только. «Декамерон» завершает его работу по переводческому обновлению наиболее значимых памятников ренессансной литературы и составляет вместе с переводами «Дон Кихота» Сервантеса и «Гаргантюа и Пантагрюэля» Рабле своего рода триптих. Переводческая программа Любимова в целом вписывается в парадигму «советской школы» перевода (он же «реалистический», он же «творческий»). О ее лидере и главном теоретике Любимов отзывался неоднозначно ${ }^{1}$, но по крайней мере разделял его взгляды на то, что является самым тяжким пороком, с которым нужно бороться на ниве художественного перевода. «Художественный перевод, как поэтический, так и прозаический, - искусство. Искусство - плод творчества. А творчество несовместимо с буквализмом» [Любимов 2012: 9] — такими словами открывается его книга о переводе ${ }^{2}$.

Если позицию Любимова можно считать вполне определенной, то о Веселовском этого не скажешь. «Декамерон» - единственный его переводческий опыт, а несколько слов, сказанных в предисловии ко второму изданию, - едва ли не единственное его высказывание о принципах перевода (своего в первую

${ }^{1} \mathrm{C}$ одной стороны, «неутомимый и страстный борец за истинно художественный перевод Иван Александрович Кашкин...» [Любимов 2012: 71], но с другой (в неподцензурных мемуарах), «Кашкин был человек психически больной, неуравновешенный, мнительный, подозрительный (...) Талантливый человек, Кашкин растрачивал себя на недостойные выпады против тех, кого он избрал постоянной своей мишенью. На любом сборище переводчиков Кашкин с маниакальной привязчивостью бубнил одно и то же, одно и то же» [Любимов 2004: 343]. Характерно, что в 1953 г. Любимов дал безоговорочно положительный отзыв на перевод «Пиквикского клуба» А. В. Кривцовой и Е. Л. Ланна, который Кашкин последовательно критиковал начиная с 1930-х годов, а в статье 1952 г. подверг настоящей травле [Азов 2013: 132-133].

${ }^{2}$ В мемуарах свое неприятие буквализма Любимов возводил еще к детским годам, к урокам, полученным от матери. 
очередь, но не только). Поставив себе целью «произвести, хотя бы приблизительно, впечатление, какое мы выносим из чтения подлинника» (что далеко не оригинально), Веселовский полагал (а это уже совсем не самоочевидно), что такой перевод «предполагает читателей, знакомых с историческим развитием изящного, чутких к оттенкам стиля, свойственным той или другой эпохе или тому или другому писателю, к наслоениям нашего поэтического словаря» [Веселовский 1992: xviii-xix]. Нетривиальность позиции Веселовского состоит в том, что переводчики XIX в., как правило, ориентировались явно или неявно на читателя демократического, иными словами малоподготовленного, в очень небольшой степени знакомого с «историческим развитием изящного» (зачастую с этим развитием мало были знакомы и они сами) ${ }^{3}$.

Ко всему прочему даже степень личного вклада Веселовского в перевод «Декамерона», что стало выясняться только сейчас, вызывает некоторые вопросы. Как установил в процессе подготовки академического издания (на время написания настоящей статьи еще не увидевшего свет) Л. В. Бессмертных, инициатива публикации русского «Декамерона» исходила не от Веселовского, а от издательства (московское Товарищество печатного дела и торговли «И. Н. Кушнерев и К»), которое заключило с академиком договор о редактировании перевода, выполненного неким Павлом Дворжаком (лицо неидентифицированное, Л. В. Бессмертных считает, что это псевдоним, под которым скрывался П. П. Кончаловский, пайщик издательства Кушнерева, поддерживавший в ходе издания с Веселовским активную переписку). Поначалу Веселовский ограничивался редактурой, затем, когда выяснилось, что перевод, с которым он работал, неудовлетворителен, оплата Веселовскому была повышена и из издательских анонсов исчезло уведомление о переводе «под редакцией А. Н. Веселовского» (замененное на «перевод А. Н. Веселовского»). Когда наступил этот момент и окончательно ли Веселовский прекратил опираться на перевод Дворжака, установить не удалось - прежде всего потому, что в архиве ученого сохранилось очень мало свидетельств его работы над «Декамероном» (за исключением рукописи «Дня Пятого», которая позволяет заключить, что на данном этапе он продолжал редактировать чужой перевод). Но во всяком случае уже при подготовке второго издания представитель издательства, обращаясь к Веселовскому, заявлял: «Вы перевели “Декамерона”, частью пользуясь переводом Дворжака, по нашему заказу».

Перевод Веселовского действительно весьма точен, тут комплименты в его адрес вполне заслуженны. Ошибок микроскопически мало, и все они носят характер некоторой невнимательности. Например, в новелле II, 7 читаем: «так как она знала его язык» (надо: «так как он знал ее язык», sappiendo la lingua di lei) и «им отвели комнату на носу» (надо: «на корме», nella poppa). Любопытно, что эти ошибки повторяет Любимов («так как она понимала его язык», «им отвели помещеньице в носовой части»), так что невольно возникает подозрение, что он в сомнительных случаях сверялся с переводом Веселовского. Правда, непонятно, как в его перевод перекочевала вопиющая нелепость, возникшая в переводе Веселовского в результате явной опечатки (III,

${ }^{3}$ И именно на такого читателя будет призывать ориентироваться И. А. Кашкин, критиковавший издательство «Academia» за то, что переводы, там публиковавшиеся, были адресованы не широкому читателю, а знатоку (см.: [Азов 2013: 103]). 
3): «Если б я, не то чтобы совершила, но даже подумала о чем-либо противном его чести и жизни, то ни одна дурная женщина не была бы так достойна с о ж а л е н и я, как я» («сожаления» вместо «сожжения», mai del fuoco degna come sare'io). Тут остается только поставить знак вопроса ${ }^{4}$.

«Дословность», на которую указывал Н. Б. Томашевский, у Веселовского имеет место, с этим не поспоришь. Вот примеры калек, взятые из новеллы III, 1 и относящиеся к отдельным внутрифразовым единицам:

\section{Веселовский}

Словно черт сидит в теле

Пошли ему Господь здоровую поясницу

Явилось в душе столь сильное желание

Сообразив, что это не устроится

Если вы пустите меня

Когда он стал работать, день за днем

Говорили ему самые неприличные слова в свете

Глупый детина, выросший не по уму

Ты начинаешь задумываться о беде прежде, чем она тебя посетила

Совершенно растянувшегося

Ветер поднял ему платье спереди назад

Вошла в такое же вожделение

\section{Любимов}

Ровно бес вселился

Да ну его к богу

Весь так и загорелся желанием

Для отвода глаз

Да вы меня только пустите

Мазетто целыми днями трудился

Ругались самыми непотребными словами

Дубина... В рост пошел, а ума не нажил

Беды еще нет, а ты ее уже накликаешь

разлегшись

Ветер задрал ему одежду

Распалилась похотью оригинал

Il diavolo in corpo

Tanto il faccia Iddio san delle reni

Venne nell'animo un disidero sì grande

Avvisandosi che fatto non gli verrebbe

Se voi mi mettete costà entro

Il quale lavorando l'un dì appresso l'altro

Dicevangli le più scellerate parole al mondo

Egli è cotal giovanotto sciocco, cresciuto innanzi al senno

Tu cominci a aver pensiero del mal prima che egli ti venga

Tutto disteso

Avendogi il vento i panni dinanzi levati indietro

In quello medesimo appetito cadde

Это типичный перевод слово в слово, который ни один советский редактор, скажем, 1960-х годов в печать бы не пропустил и который в разгар войны с буквализмом клеймил еще К. И. Чуковский («чем точнее порой передаешь каждое слово переводимого текста, тем дальше от подлинника будет твой перевод» [Чуковский 1941: 224]). Конечно, в переводе Веселовского не встретишь

${ }^{4}$ У Любимова ошибки (их больше, но, впрочем, тоже немного) возникают по другой причине - из-за неверного понимания итальянского текста. Вот пара примеров. «Когда 〈...〉 Мушьятто Францези ‘...〉 отбыл в Тоскану» $(\mathrm{I}, 1)$ - в оригинале он только собирается отбыть (dovendone in Toscana venire, у Веселовского правильно: «сбирался поехать»). В новелле IV, 1 «с крайним тщанием осмотревшись, дабы никто не проник в тайну их любви, Гвискардо спустился в пещеру» - в оригинале Гвискардо не осматривается, просто любовники договариваются, как им себя не выдать (у Веселовского: «распорядившись осмотрительно, как соблюсти свою любовь в тайне»). В новелле VI, 1 вместо «как-то раз все мы были у нее в имении» надо: «она была за городом, как мы сейчас» (la quale per avventura essendo in contado, come noi siamo). 
такого откровенного насилия над языком, которое встречается в переводах XIX в., но подчас он очень близко подходит к границе, за которой это насилие начинает ощущаться: «она овладела с удивительной силой своим лицом» (ср. у Любимова: «напрягла все усилия, чтобы не перемениться в лице»), «твоя малая озабоченность выдать меня замуж» (ср. «ты не спешил с моим замужеством»), «вся моя обязанность относительно тебя совершена» (ср. «свой долг по отношению к тебе я исполнила»), «глаза, которые она, отягченная сном, держала закрытыми» (ср. «глаза, которые смежил ей глубокий сон»), «готовьтесь быть разбитыми и потопленными» (ср. «а не то мы вас одолеем и потопим в море»), «не взяв с нее ничего, кроме кое-какого поцелуя» (ср. «только успев и сорвать с ее уст поцелуй»), «я последую за тобой с чудесами силы» (ср. «на какие чудеса храбрости я способен»), «друзей, вооруженных под одеждой» (ср. «все они прятали под платьем оружие»), «сильно ударил его по голове, снеся половину ее» (ср. «ударом меча рассек ему голову надвое»). В общем, в примерах недостатка нет.

Что касается калькированного синтаксиса, еще одного замечания Н. Б. Томашевского, то и здесь спорить не приходится ${ }^{5}$. Несколько примеров:

\section{Веселовский}

Сбирался поехать в Тоскану вместе с Карлом Безземельным, братом французского короля, вызванным и побужденным к тому папой Бонифацием...
Любимов

Отбыл в Тоскану вместе с братом французского короля Карлом Безземельным, которого туда вытребовал и вызвал папа Бонифаций... оригинал (I, 1)

Dovendone in Toscana venire con messere Carlo Senzaterra, fratello del re di Francia, da papa Bonifazio addomandato e al venir promosso...

Веселовский сохраняет и синтаксический порядок (поэтому причастный оборот оказывается удален от определяемого слова), и причастный оборот (замененный у Любимова придаточным предложением), что создает тяжелую цепочку.

\section{Веселовский}

Сер Чаппеллетто 〈...〉 при том изощренном слухе, какой часто бывает у больных, услышал...

\section{Любимов}

Между тем слух у многих больных бывает особенно тонок, и он расслышал...

Веселовский пытается воспроизвести абсолютный герундий.

\section{Веселовский}

Она была так красива телом и лицом, как когда-либо бывала женщина...
Любимов

То была самая статная и самая красивая женщина в мире...

\section{оригинал $(\mathrm{I}, 1)$}

Ser Ciappelletto 〈...〉 avendo l'udire sottile, sì come le più volte veggiamo aver gl'infermi, udì...

Веселовский пытается сохранить грамматическую конструкцию.

${ }^{5}$ Хотя это изъян только с точки зрения адептов «творческого» перевода, тогда как для сторонников других подходов — основная задача переводчика [Беньямин 2004: 41-42]. 


\section{Веселовский}

Так сказав, точно у ней в голове был источник влаги, без всякого женского вопля склонившись над чашей, она принялась, плача...

\section{Любимов}

В противоположность тому, как ведут себя в таких случаях женщины, Гисмонда не испустила ни единого вопля, - она молча склонилась над кубком, и, словно в голове у нее находился источник, стала проливать...

\section{Сохраняет синтаксическую последовательность.}

\section{Веселовский}

Его настоящее имя было Галезо, но так как ни усилиями учителя, ни ласками и побоями отца, ни чьей-либо другой какой сноровкой невозможно было вбить ему в голову ни азбуки, ни нравов, и он отличался грубым и неблагозвучным голосом и манерами, более приличными скоту, чем человеку, то все звали его как бы на смех Чимоне.

\section{Любимов}

Как ни бился с ним учитель, как ни старался пронять его лаской и таской отец, на какие только ухищрения ни пускались другие - учение ему так и не далось, он так и не пообтесался, голос у него был грубый и для ушей несносный, вообще это был не человек, а животное - вот почему, хотя настоящее имя его было Галезо, все в насмешку называли его «Чимоне». оригинал (IV, 1)

E così detto, non altramente che se una fonte d'acqua nella testa avuta avesse, senza fare alcun feminil romore, sopra la coppa chinatasi piagnendo cominciò... оригинал $(\mathrm{V}, 1)$

Il cui vero nome era Galeso; ma per ciò che mai né per fatica de maestro né per lusinga o battitura del padre o ingegno d'alcuno altro gli s'era potuto meter nel capo né lettera né costume alcuno, anzi con la voce grossa e deforme e con modi più convenienti a bestia che a uomo, quasi per ischerno da tutti era chiamato Cimone.

Любимов переносит начало фразы ближе к концу, а началом делает разъединяющую их подчинительную конструкцию, - Веселовский строго следует за синтаксисом оригинала.

\section{Веселовский}

Когда Чимоне увидел ее, опершись на посох и не говоря ни слова, точно никогда дотоле не созерцал женского образа, он с величайшим восхищением принялся...

\section{Любимов}

Узрев ее, Чимоне оперся на посох и молча, с неизъяснимым восторгом, как будто впервые видел женщину, устремил на нее.. оригинал (V, 1)

La quale come Cimone vide, non altramente che se mai più forma di femina veduta non avesse, fermatosi sopra il suo bastone, senza dire alcuna cosa, con ammirazion grandissima la incominciò...

Поскольку Веселовский в основном сохраняет синтаксическую последовательность оригинала, то выходит, что Чимоне изумился при виде Ифигении настолько, что оперся на посох.

Что касается лексики, то впечатление, будто Веселовский излишне архаизировал язык перевода (А. Л. Штейн), возникнуть может, но продуцируется не сознательной установкой переводчика, а естественным старением языка. Когда Веселовский говорит о Чаппеллетто, что тот готов был составлять ложные акты «по востребованию» («по первому требованию» у Любимова), то это не 
архаизм, а для его времени нормальное словоупотребление (у А. Амфитеатрова, скажем, это слово встречается в сходном смысле не один раз). Точно таким же нормальным словоупотреблением является оборот «во всю его жизнь» (у Любимова, естественно, «за всю его жизнь») - его можно встретить у Лескова, Мережковского, Дорошевича и далее, вплоть до Даниила Данина. «В возмездие» в смысле «в награду» - также для XIX в. норма. Некоторые устарелости в переводе Веселовского попадаются, но их так немного, что они никак не могут возникать как результат программной установки. Искусственно состарить язык Веселовский не пытался - это можно утверждать вполне определенно. Это пытался сделать Любимов. У него мы находим «сей» (когда у Веселовского «этот»), «коего» (ср. «которого»), «платье» (ср. «одежда»), «молвила» (ср. «сказала»), «узрел» (ср. «увидел»), «чаял» (ср. «нуждался»), «инок» (ср. «монах»), «всечасный» (ср. «бесконечный»), «всеправедный» («такой судия, как он») и пр. В этом отношении Любимов занимает особую позицию в рамках школы «советского перевода», поскольку ее главные теоретики, и К. И. Чуковский, и И. А. Кашкин, против воспроизведения «возраста языка» выступали весьма активно. «Архаических вычур» он избегал, но «словесный колорит эпохи» передать пытался - с помощью всякого рода «стилистических мелочей» [Любимов 2012: 125-127]. Переводя Боккаччо, он искал эти «мелочи», по его собственным словам, у русских писателей XVIII - начала XIX в., Сумарокова, Хераскова, Богдановича, Княжнина, Капниста и др. [Там же: 92].

Переводы Любимова заслуженно славятся своим языковым богатством. Но и перевод Веселовского лексически бледным никак не назовешь: В. Ф. Шишмарев отнюдь не преувеличивал, когда говорил о его «богатейшем словаре». Одной из тенденций отбора слов из этого лексикона является русификация, но не агрессивная и не тотальная. «Местечко» (castello), «горница» (camera), «хутор» (possessione), «околоток» (paese) — это и сравнить нельзя с тем, что позволял себе самый популярный в XIX в. переводчик европейской прозы Иринарх Введенский (см.: [Левин 1985: 138-140]), не говоря уж о таких казусах, как «Илиада» Б. Ордынского. Столь же невелик и объем того, что во времена Веселовского воспринималось как просторечие и что проявляется у него только на уровне отдельных слов: «прилучиться» («не прилучилось с ним того...»), «стакиваться» (в смысле «заигрывать»), «похватки» (в смысле «привычное действие», «навык»).

Чего Веселовский совершенно не пытается воспроизвести, так это разнообразный риторический инструментарий «Декамерона» - инверсии, параллелизмы, клаузулы, рифмы, стихоподобный ритм (см.: [Бранка 1983: 58-101]). Вот знаменитое начало «Декамерона»:

Веселовский
Соболезновать удручен-
ным - человеческое свой-
ство, и хотя оно пристало
всякому, мы особенно ожи-
даем его от тех, которые
сами нуждались в утешении
и находили его в других.

Веселовский

Любимов

Соболезновать страждущим - черта истинно человеческая, и хотя это должно быть свойственно каждому из нас, однако ж в первую очередь мы вправе требовать участия от тех, кто сам его чаял и в ком-либо его находил.

\section{оригинал}

Umana cosa è aver compassione degli afflitti: e come che a ciascuna persona stea bene, a coloro è massimamente rich e s to li quali già hanno di conforto avuto mestiere e hannol trovato in alcuni. 
В оригинале в этой фразе четырежды встречается курсус планус (выделено разрядкой) - в переводах этого, конечно, нет, но Любимов дважды прибегает к инверсии («черта истинно человеческая», «в ком-либо его находил»), пытаясь таким способом подчеркнуть ритмическую маркированность периода. Инверсии он вообще не избегает («всечасным подвергается опасностям»), хотя и ее использует довольно скупо (тогда как в оригинале она постоянна). Замечает он и рифмы: «рассказчик не занимательный, но человек проницательный» (Era molto migliore intenditor che novellatore, VI, 1, у Веселовского: «более чуткий к намекам, чем хороший рассказчик», без всякой рифмы). Пытается с помощью соответствующей лексики выделить места, в которых угадывает присутствие высокого стиля («Ты достигнуло м е ты, к коей стремится всякий, ты покинуло сию плачевную юдоль с ее скорбями»). Веселовский тоже помнит о том, что речь Боккаччо «всегда несколько торжественно поднята» [Веселовский 1992: хіiі], но прибегать для ее передачи к риторическим приемам в свой антириторический век не рискует.

Хотя Любимов и говорил, что, работая над переводом «Декамерона», обращался в поисках образцов к русскому XVIII в., ни Сумароков, ни Херасков следов здесь не оставили. Язык любимовского «Декамерона» — это обобщенный литературный язык XIX-XX вв., умеренно инкрустированный славянизмами, без модернизаций и почти без словесной изобретательности, свойственной, к примеру, переводу Рабле. Какую-то особую дикцию для своего «Декамерона» он выработать не пытался. Перевод блестящий, слов нет, но полностью укладывающийся в рамки основных переводческих моделей своего времени.

Нельзя сказать, что перевод Веселовского из таковых выламывается. Буквализм XIX веку был известен, но либо в качестве нежелательного эффекта от конвейерной работы журнальных переводчиков, либо в качестве принципиального подхода к переводу стихотворной классики, и в последнем случае (в случае переводческой деятельности Афанасия Фета, к примеру) он был подвергнут более или менее единодушному осуждению. И опыт Веселовского, как мы помним, был встречен на первых порах отнюдь не всеобщей овацией, зато без всяких проблем вошел в эпоху буквализма, явившись своего рода предтечей деятельности А. Франковского и Е. Ланна: не случайно его «Декамерон» пять раз выходил в издательстве «Academia» именно в 1927-1933 гг. (но затем, после победы над буквализмом, переиздавался только дважды, пока на исходе советской эпохи монополия «творческого» перевода не была поставлена под сомнение). Веселовский, придерживаясь в своем переводе и лексического, и синтаксического буквализма, порой подвергает язык существенным перегрузкам (хотя и не прямой ломке, как, например, в брюсовской «Энеиде»), но именно благодаря этому остранению, этому языковому сдвигу, этой дикции, не имеющей в русской языковой традиции прямых аналогов, заполняет ту пустоту, которая образована отсутствием в русской литературной традиции аналогов «Декамерона». Заполняет далеко не до конца, риторические убранства «Декамерона» он отвел в сторону, но в целом можно утверждать, что это принципиально иной, чем у Любимова, тип перевода, приближающий не оригинал к читателю, а читателя к оригиналу ${ }^{6}$. Не случайно для правильного восприятия его перевода ему требовался читатель, знакомый с «историческим развитием изящного».

${ }^{6}$ Разграничение М. Л. Гаспарова, которое встречается во многих его работах, впервые в [Гаспаров 1971: 110-113]. 


\section{Литература}

Азов 2013 - Азов А. Поверженные буквалисты. Из истории художественного перевода в СССР в 1920-1960-е годы. М.: Изд. дом Высшей школы экономики, 2013.

Алексеев 1939 - Алексеев М. П. Комментарии // Веселовский А. Н. Избранные статьи / Под общ. ред. М. П. Алексеева и др.; Вступ. ст. В. М. Жирмунского, А. А. Смирнова; Коммент. М. П. Алексеева. Л.: Гос. изд-во «Худ. лит.», 1939. C. 521-571.

Беньямин 2004 - Беньямин В. Задача переводчика / Пер. И. Алексеевой // Беньямин В. Маски времени: Эссе о культуре и литературе / Сост., предисл. и примеч. А. Белобратова. СПб.: Симпозиум, 2004. С. 27-46.

Бранка 1983 - Бранка В. Боккаччо средневековый. М.: Радуга, 1983.

Веселовский 1992 - [Веселовский А. Н.] Вместо предисловия. Предисловие ко II-му изданию // Боккаччо Дж. Декамерон: В 2 т. / [Пер. и предисл. А. Н. Веселовского]. Репринтное воспроизведение [изд. 1896 г.]. М.: Наука, 1992. Т. 1. С. іх-хxvi.

Гаспаров 1971 - Гаспаров М. Брюсов и буквализм (по неизданным материалам к переводу «Энеиды») // Мастерство перевода. Сб. 8. М.: Сов. писатель, 1971. C. $90-128$.

Левин 1985 - Левин Ю. Д. Русские переводчики XIX века и развитие художественного перевода. Л.: Наука, 1985.

Любимов 2004 - Любимов Н. М. Неувядаемый цвет: Книга воспоминаний: [В 3 т.]. Т. 2. М.: Языки русской культуры, 2004.

Любимов 2012 - Любимов Н. Книга о переводе. М.: Б.С.Г.-Пресс, 2012.

Новые книги 1892 - Новые книги // Северный вестник. 1892. № 3. С. 49-77.

Томашевский 1970 - Томашевский Н. Примечания // Боккаччо Дж. Декамерон / Вступ. ст. Р. Хлодовского; Пер. Н. Любимова под ред. Н. Томашевского; Пер. стихов Ю. Корнеева. М.: Худ. лит., 1970 (Б-ка всемирн. лит.; Сер. первая; Т. 29). C. 663-688.

Хлодовский 1992 - Хлодовский Р. И. О переводе и переводчике // Боккаччо Дж. Декамерон: В 2 т. / [Пер. и предисл. А. Н. Веселовского]. Репринтное воспроизведение [изд. 1896 г.]. М.: Наука, 1992. Т. 2. С. 337-340.

Чуковский 1941 - Чуковский К. Высокое искусство. М.: Гос. изд-во «Худ. лит.», 1941.

Шишмарев 1927 - Шиимарев В. «Декамерон» Боккаччьо // Боккаччьо Дж. Декамерон / Пер. А. Веселовского, со вступ. ст. В. Ф. Шишмарева и предисл. П. С. Когана. Л.: Academia, 1927. Т. 1. С. xiii-xxvi.

Штейн 1955 - Штейн А. Джованни Боккаччо и его «Декамерон» // Боккаччо Дж. Декамерон / Пер. А. Н. Веселовского. М.: Гос. изд-во худ. лит., 1955. С. 3-25.

\section{References}

Alekseev, M. P. (1939). Kommentarii [Commentaries]. In A. N. Veselovskii. Izbrannye stat' $i$ [Selected articles], 521-571. Leningrad: Gosudarstvennoe izdatel'stvo "Khudozhestvennaia literatura". (In Russian).

Azov, A. (2013). Poverzhennye bukvalisty. Iz istorii khudozhestvennogo perevoda $v$ SSSR $v$ 1920-1960-e gody [Literalists vanquished. From the history of literary translation in the USSR during the 1920s-1960s]. Moscow: Izdatel'skii dom Vysshei shkoly ekonomiki. (In Russian). 
Ben'iamin, V. (2004). Zadacha perevodchika [Trans. from Benjamin, W. (1923). Die Aufgabe des Übersetzers. In Ch. Baudelaire. Tableaux parisiens, vi-xvii. Heidelberg: R. Weissbach]. In V. Ben'iamin [= W. Benjamin]. Maski vremeni: Esse o kul'ture i literature [The masks of time: Essays on culture and literature], 27-46. St. Petersburg: Simpozium. (In Russian).

Branka, V. (1983). Bokkachcho srednevekovyi [Medieval Boccaccio]. Moscow: Raduga. (In Russian).

Chukovskii, K. (1941). Vysokoe iskusstvo [The high art]. Moscow: Gosudarstvennoe izdatel'stvo "Khudozhestvennaia literatura”. (In Russian).

Gasparov, M. (1971). Briusov i bukvalizm (Po neizdannym materialam k perevodu "Eneidy") [Briusov and literalism. Based on unpublished materials for his translation of the Aeneid]. In Masterstvo perevoda [The craft of translation] (Book 8), 90-128. Moscow: Sovetskii pisatel'. (In Russian).

Khlodovskii, R. I. (1992). O perevode i perevodchike [On translation and the translator]. In Dzh. Bokkachcho [= G. Boccaccio]. Dekameron [The Decameron] (Vol. 2), 337-340. Moscow: Nauka. (In Russian).

Levin, Iu. D. (1985). Russkie perevodchiki XIX veka i razvitie khudozhestvennogo perevoda [Russian translators in the $19^{\text {th }}$ century and the development of literary translation]. Leningrad: Nauka. (In Russian).

Liubimov, N. M. (2004). Neuviadaemyi tsvet: Kniga vospominanii [The unfading bloom: A book of memories] (Vol. 2). Moscow: Iazyki russkoi kul’tury. (In Russian).

Liubimov, N. (2012). Kniga o perevode [A book on translation]. Moscow: B.S.G.-Press. (In Russian).

Novye knigi [New books] (1892). Severnyi vestnik [The Northern Herald], 1892(3), 49-52. (In Russian).

Shishmarev, V. (1927). “Dekameron” Bokkachch'o [Boccaccio's Decameron]. In Dzh. Bokkachch'o [= G. Boccaccio]. Dekameron [The Decameron] (Vol. 1), xiii-xxvi. Leningrad: Academia. (In Russian).

Shtein, A. (1955). Dzhovanni Bokkachcho i ego "Dekameron" [Giovanni Boccaccio and his Decameron]. In Dzh. Bokkachcho [= G. Boccaccio]. Dekameron [The Decameron], 3-25. Moscow: Gosudarstvennoe izdatel'stvo khudozhestvennoi literatury. (In Russian).

Tomashevskii, N. (1970). Primechaniia [Notes]. In Dzh. Bokkachcho [= G. Boccaccio]. Dekameron [The Decameron], 663-687. Moscow: Khudozhestvennaia literatura. (In Russian).

[Veselovskii, A. N.] (1992). Vmesto predisloviia. Predislovie ko II-mu izdaniiu [Instead of an introduction. Introduction for the $2^{\text {nd }}$ edition]. In Dzh. Bokkachcho [= G. Boccaccio]. Dekameron [The Decameron] (A. N. Veselovskii, Trans. and Intro.) (Reprint ed., 1896) (2 vols.). (Vol. 1), ix-xxvi. Moscow: Nauka. (In Russian). 


\section{Информация об авторе}

Михаил Леонидович Андреев

доктор филологических наук член-корреспондент РАН

главный научный сотрудник, отдел классических европейских литератур и сравнительного литературоведения, Институт мировой литературы им. А. М. Горького РАН Россия, 121069, Москва, ул. Поварская, d. $25 a$

Тел.: + 7 (495) 690-50-30 ведущий научный сотрудник, Лаборатория историко-литературных исследований, Школа актуальных гуманитарных исследований, Российская академия народного хозяйства и государственной службы при Президенте РФ Россия, 119571, Москва, пр-т Вернадского, д. 82 Тел.: + 7 (917) 532-69-00 ведуший научный сотрудник, Институт гуманитарных историкотеоретических исследований им. А. В. Полетаева, Национальный исследовательский университет «Высшая школа экономики» Россия, 105066, Москва, ул. Старая Басманная, д. 21/4, корп. Л Тел.: + 7 (495) 772-95-90 -mikhailandreev1@gmail.com

\section{Information about the author}

Mikhail L. Andreev

Dr. Sci. (Philology)

Corresponding Member of RAS

Leading Researcher,

Department of Classical Western Literature and Comparative Literary Studies, A. M. Gorky Institute of World Literature of the Russian Academy of Sciences Russia, 121069, Moscow, Povarskaya Str., $25 a$

Tel.: + 7 (495) 690-50-30

Leading Researcher,

Laboratory of Historical and Literary

Studies, School of the Advanced Studies in the Humanities, The Russian Presidential Academy of National Economy and Public Administration

Russia, 119571, Moscow,

Prospect Vernadskogo, 82

Tel.: +7 (917) 532-69-00

Leading Researcher,

Poletayev Institute for Theoretical and Historical Studies in the Humanities,

National Research University Higher School of Economics

Russia, 105066, Moscow, Staraya

Basmannaya Str., 21/4, Corp. L,

Tel.: + 7 (495) 772-95-90

•mikhailandreev1@gmail.com 